\title{
An Evaluation of Three-Dimensional Scans of the Time-Dependent Volume Changes in Bone Grafting Materials
}

\author{
Tihomir Georgiev ${ }^{1}$, Stefan Peev ${ }^{2}$, Hristina Arnautska ${ }^{3}$, Albena Gencheva ${ }^{1}$, Ivan Gerdzhikov $^{4}$ \\ ${ }^{1}$ Department of Oral and Maxillofacial Surgery, Faculty of Dental Medicine, Medical University of Varna \\ ${ }^{2}$ Department of Periodontology and Dental Implantology, Faculty of Dental Medicine, Medical University of Varna \\ ${ }^{3}$ Department of Ortodontics, Faculty of Dental Medicine, Medical University of Varna \\ ${ }^{4}$ Department of Prosthetic dentistry, Faculty of Dental Medicine, Medical University of Sofia
}

\begin{abstract}
Introduction: It is essential for the dental implantologist to be aware of the time-dependent volume changes that could occur in the augmentation material. Should the implant placement stage be delayed in time, the dental clinician must select the appropriate bone grafting material for the specific case. Materials and methods: 35 patients were eligible for inclusion, divided into 4 groups, who had a planned maxillary sinus floor augmentation procedure with different bone replacement materials: Group 1 (10 patients) - Bone Ceramic (a synthetic biphasic calcium phosphate material,consisting of hydroxyapatite and $\beta$-tricalciumphosphatein a ratio of 60:40). Group 2 (10 patients) - Cerabone(Xenogenic bone material from the mineral phase of bovine bone). Group 3 (10 patients) - Maxresorb inject(Calcium phosphate paste, composed of $80 \%$ nano-hydroxyapatite aquagel and $20 \%$ biphasic calcium phosphate granules). Group 4 (5 patients) - Collagen fleece absorbedin venous blood. Results: The various bone grafting materials applieddemonstrated differentvolume loss over time following a maxillary sinus floor augmentation procedure. The least volume loss over time was found in the application of Xenogenic bovine hydroxyapatite material (XBHM), and most volume contraction was observed in the use of Biphasic calcium phosphate paste material (ВСРPM). Conclusions:In maxillary sinus floor augmentation procedures the application of Xenogenic bone material from the mineral phase of bovine bone as an augmentation material has proven to maintain its volume the longest in comparison with other bone grafting materials.
\end{abstract}

Keywords: 3D computed tomography; sinus floor elevation; volumetric stability

\section{Introduction}

The clinical monitoring of the application outcome of bone grafting materials in oral surgery has been facilitated by the use of non-invasive diagnostic methods.[1]

Bone remodeling that occurs following a bone grafting procedure in the maxillary sinus was first studied using twodimensional imaging.[2] In1996 Nyström et al. [3] attempted to evaluate the volume lossof bonereplacement materialusing panoramic radiographs, showing changes in the height and width of the bone graft. Computed tomography and three-dimensional imagingassist the oral surgeon in determining the individual anatomical structures shape and volume, and evaluating the changes in the graftvolume loss over time with high accuracy.[4, 5]

Baciut M. et al. [6]performed a pre- and postoperative assessment of the maxillary sinuses on 13 patients (16 sinuses)witha planned sinus augmentation procedure, using panoramic radiographs (OPG) and CBCT scans. The study comprised choice of treatment, timing of implant placement, sinus morphology, complication prediction and graft volume assessment.A preoperative planning based on CBCT provides better diagnostics and a more precise postoperative monitoring.

Shanbhag S.et al.[7]systematically reviewed the available literature on graft volume changes after sinus augmentation with different biomaterials using three-dimensional
images.Seven controlled and five uncontrolled studies (234 sinus lifts) were included and reported on a range of graft materials.Autogenous bone was used in the particulate or block form.Bone substitutes were used either alone or in combination with other materials as composite grafts. All studies reported reductions in bone graft volumes over time, generally after 6 months to 6 years. Substantial reduction of the bone graft volume (approximately $45 \%$ in 77 sinus lifts) was reported for autogenous bonegrafts after 6 months and up to 2 years. Reductions in augmentationvolumes over time for alloplastic materials were relatively lower (approximately $18 \%$ to $22 \%$ in 142 sinus lifts).

Nishida T. et al. [8] presented radiological findings of a CBCT study oftrans-crestal sinus floor elevation, using autogenous bone as the augmentation material. 91 implants on 52 patients were subsequently placed in the regenerated bone. The 6-month follow-up CBCT study demonstrated resorption of the grafted augmentation material but at least $1 \mathrm{~mm}$ of grafted augmentation material was recognized around the implant fixtures.

Gorla LF. et al. [9]carried out a study comparing the changes in bone volume after maxillary sinus lifting using 3 different bone replacement materials: autogenous bone $(n=12)$, autogenous bone associated with beta-tricalcium phosphate $(\beta$-TCP $)(n=9)$, and $\beta$-TCP alone.The change in bone graft volume was evaluated 6 months postoperative in each group.The results showed an average resorption of $45.7 \pm$ 


\section{International Journal of Science and Research (IJSR) \\ ISSN (Online): 2319-7064}

Index Copernicus Value (2015): 78.96 | Impact Factor (2015): 6.391

$18.6 \%$ for the first group, $43.8 \pm 18.4 \%$ for the second group, and $38.3 \pm 16.6 \%$ for the third group.

Berberi A.et al. [10]performed a detailed retrospective study to quantify volumetric bone graft changes over a two-year period in maxillary sinuses augmented with a mineralized cortical bone allograft material. 11 patients $(6$ males and 5 females) with mean age of 51.6 years underwenta maxillary sinus floor augmentation procedure.CBCT scans were taken within the first 2 weeks after the maxillary sinus lift, immediately before implant placement (4 months after grafting)and after 1 year of implant loading.Mean graft volume was $16.24 \pm 1.54 \mathrm{~cm}^{3}$ at the first two weeks, $14.48 \pm 1.48 \mathrm{~cm}^{3}$ after 4 months and $13.06 \pm 1.39 \mathrm{~cm}^{3}$ after 2 years, i.e. the retrospective investigation demonstrated a $20.63 \%$ decrease in graft volume for the entire follow-up period.

Soardi CM. et al. [11] verified the diagnostic potential of $\mathrm{CBCT}$ on the evaluation of bone regeneration, comparing data from the 3-D scans and the data frommicroradiographic analyses of bone biopsy samples. The authors concluded that the data obtained from the CBCTscans did not differ statistically from the biopsy data.

Mazzocco F.et al. [12] performed a three-dimensional radiographic study of $100 \%$ anorganic bovine bone xenograft as a bone replacement material of good stability in time. A maxillary sinus augmentation procedure was done in 20 patients. A CBCT scan of the augmentedsite was taken immediately after the procedure and 8 to 9 months later. The mean graft volume was $1,432 \pm 539 \mathrm{~mm}^{3}$ and $1,287 \pm 498$ $\mathrm{mm}^{3}$ respectively for the period right after surgery and the 89 months after surgery, demonstrating a significant difference in graft volume by paired t-test $(\mathrm{P}=.01)$, meaning a graft volume contraction of $10 \%$.

Liu Y.et al. [13] conducted an elaborate research on maxillary sinus floor augmentations using Bio-Oss aloneover a 6-month comparative period. The authors took CBCT scans right after grafting and 6 months later,revealing a bone height gain of $14.19 \pm 2.02 \mathrm{~mm}$ immediately after augmentation, whichstabilized at $13.68 \pm 1.95 \mathrm{~mm}$ after the bone healing period.

Umanjec-Korac S. et al. [14] analyzed the resorption rate of deproteinized bovine bone material used alone as well as mixed with autologous bone chipsas graft material. A retrospective analysis of 29 augmented sinuses in 19 patients was conducted and CBCT scans of the augmented sinuses were obtained pre- and post-operatively up to 2-year followup.The results indicatedsimilar graft volume resorption for both groups of approximately $20 \pm 10 \%$.

Ohe JY.et al. [15] applied biphasic calcium phosphate as augmentation material grafted in the maxillary sinus. The objective of the study was to confirm the stabilityof grafted volume overtime by 3-D CT. From 2009 to 2011, 15 patients were included in the study, 8 male and 7 female of mean age 50.1 years.For the sinus floor augmentation procedure, biphasic calcium phosphate with local blood was packed loosely into the maxillary sinus and the grafted site was covered with a collagen membrane. For the evaluation of volume change, 3D CBCT scans were taken pre-operatively, 1 week post-operatively, 1 month, 3 months, and 6 months later. $84.32 \%$ of the grafted biphasic calcium phosphate was maintained until 6 months later, and the average volume loss was $207.7 \mathrm{~mm}^{3}$, indicating a significant volume change (decreasing).

An interesting series of clinical cases have been presented byAtef $M$. et al.[16], investigating the use of a titanium micromesh for lateral-windowsinus floor elevation without bone grafting. The 3-D scans showed that the initial residual ridge height was $3.6 \mathrm{~mm} \pm 1.6 \mathrm{~mm}$ prior to surgery, while 6 months postoperativelyit reached $9.63 \mathrm{~mm} \pm 1.47 \mathrm{~mm}$. However, the study did not provide any follow-up results since the removal of the titanium micromesh.

Kim ES. et al. [17] suggested a more thorough investigation in an attempt to assess the efficacy of a bioabsorbable membrane to maintain the level of the aaugmentedsinus floor of 14 patients. Using CBCT scans they carried out volumetric analysis of the augmentation volume of a sinus graft over time: before surgery, immediately after surgery, 6 months after surgery, and 1 year after surgery.Overall, the average percent volume of graft material that remained 6 months after implantation was $82.0 \%$, and the average percent volume of graft material that remained 1 year after surgery was $60.4 \%$. The reductions were shown to be statistically significant $(\mathrm{P}=0.002$ and $\mathrm{P}<0.001$, respectively).

The literature review above proves that CBCT is indeeda reliable method inpreoperative planning. Based on numerous studies, the conclusion follows that when comparing OPG, segment radiology and computerizedaxial tomography withCone Beam Computed Tomography (CBCT), the latter method is superior when analyzingthe anatomical features of areas in the maxillofacial region.

Maxillary sinus floor augmentation is a surgical procedure requiringdetailed preoperative diagnostic evaluation. First the clinician ought to establish the absence of inflammation in the maxillary sinus cavities which could eventually prevent the integration of the augmentation material. The clinician also has to analyze the morphology of the anatomical box and to locate the passage of critical vessels and organs which couldin turn hinder the surgical intervention. It is also essential to consider the success of the surgery in long-term time perspective.

The dental literature available on the subject proves insufficient as there are many controversial issues that demand further investigation.Therefore, we carried out a study using CBCT which also included diagnostics ofthe anatomical features of the maxillary sinus, thus enabling the oral surgeon toprepare for the sinus floor augmentation procedure and follow up the results of surgery.

\section{Materials and methods}

A comparative study was performed of the volume of the bone graft material immediately after the maxillary sinus floor augmentation procedure and 3 years postoperatively.

\section{Volume 6 Issue 1, January 2017




\section{International Journal of Science and Research (IJSR) \\ ISSN (Online): 2319-7064 \\ Index Copernicus Value (2015): 78.96 | Impact Factor (2015): 6.391}

35 patients were eligible for inclusion, divided into 4 groups, who had a planned maxillary sinus floor augmentation procedure with different bone replacement materials:

Group 1 (10 patients) - Bone Ceramic (a synthetic biphasic calcium phosphate material,consisting of hydroxyapatite and $\beta$-tricalciumphosphatein a ratio of $60: 40)$

Group 2 (10 patients) - Cerabone(Xenogenic bone material from the mineral phase of bovine bone)

Group 3 (10 patients) - Maxresorb inject(Calcium phosphate paste, composed of $80 \%$ nano-hydroxyapatite aquagel and $20 \%$ biphasic calcium phosphate granules)

Group 4 (5 patients) - Collagen fleece absorbedin venous blood

CBCT scans were taken on Day 12 after the maxillary sinus floor augmentation procedure to evaluate the state of the sinus and the bone graft. (Figures 1, 2, 3). The scans were acquired with a cone-beam computedtomography scanner
(Planmeca ProMax 3D Max), integrated with a computer hard drive andbackup peripheral devices, software for reconstructing images (Planmeca Romexis) and apatients registration program. Scanning parameters were: scanning time 9-40 sec., imagereconstruction time 2-55 sec. CBCT images were stored and read by Planmeca Romexissoftware, compatible with Windows XP, Windows 7 and Windows 8.Six to nine months following themaxillary sinus floor augmentation procedure,the dental implant area was identified and the implants were placed. Three or four months later the implant prosthetic loading took place.

Thirty-six months after the first surgery, all patients were referred for a follow-up scan (Figure 4) in order to evaluate the time-dependent volume maintenance and resorption of the bone augmentationmaterials most commonly used in dental implantology practice.The images were used to examine the state of the maxillary sinus and to determine the height of augmented subantral bone in the site of subsequent biopsy. The findings of the scans were compared and qualitativeand quantitative analyses were performed.

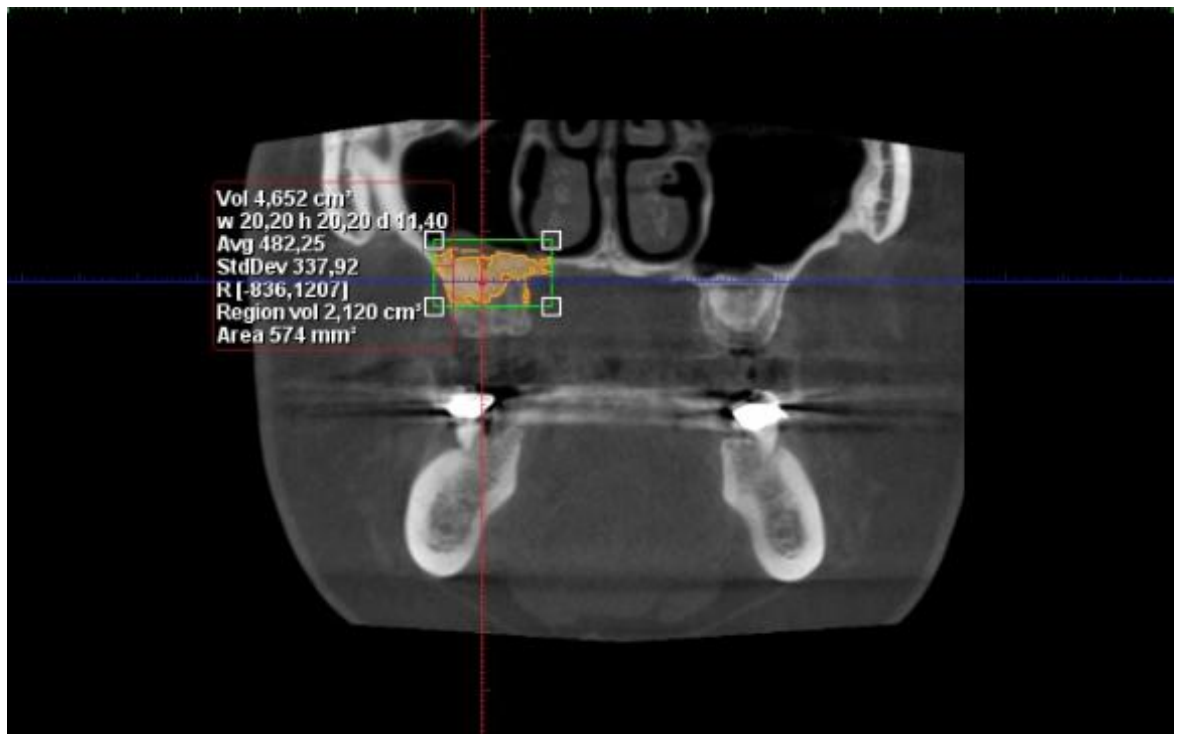

Figure 1: Measuring the bone graft volume following a maxillary sinus floor augmentation procedure

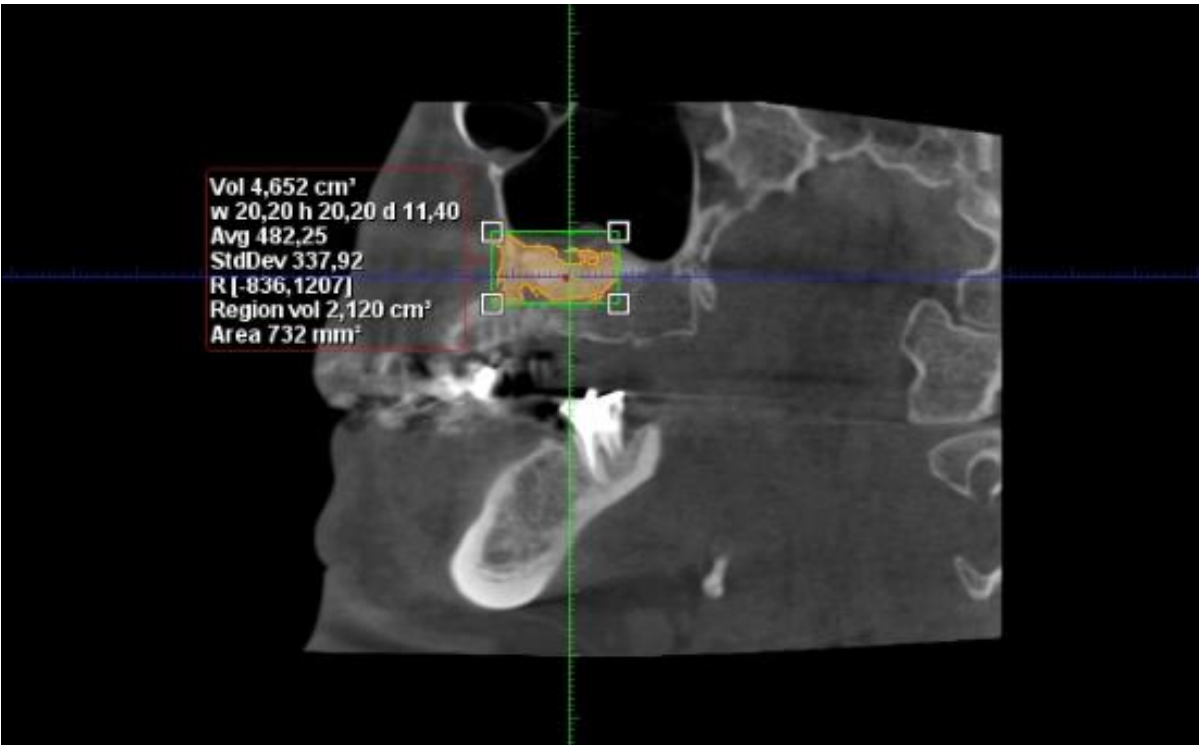

Figure 2: Measuring the bone graft volume following a maxillary sinus floor augmentation procedure

\section{Volume 6 Issue 1, January 2017 www.ijsr.net}




\section{International Journal of Science and Research (IJSR) \\ ISSN (Online): 2319-7064}

Index Copernicus Value (2015): 78.96 | Impact Factor (2015): 6.391

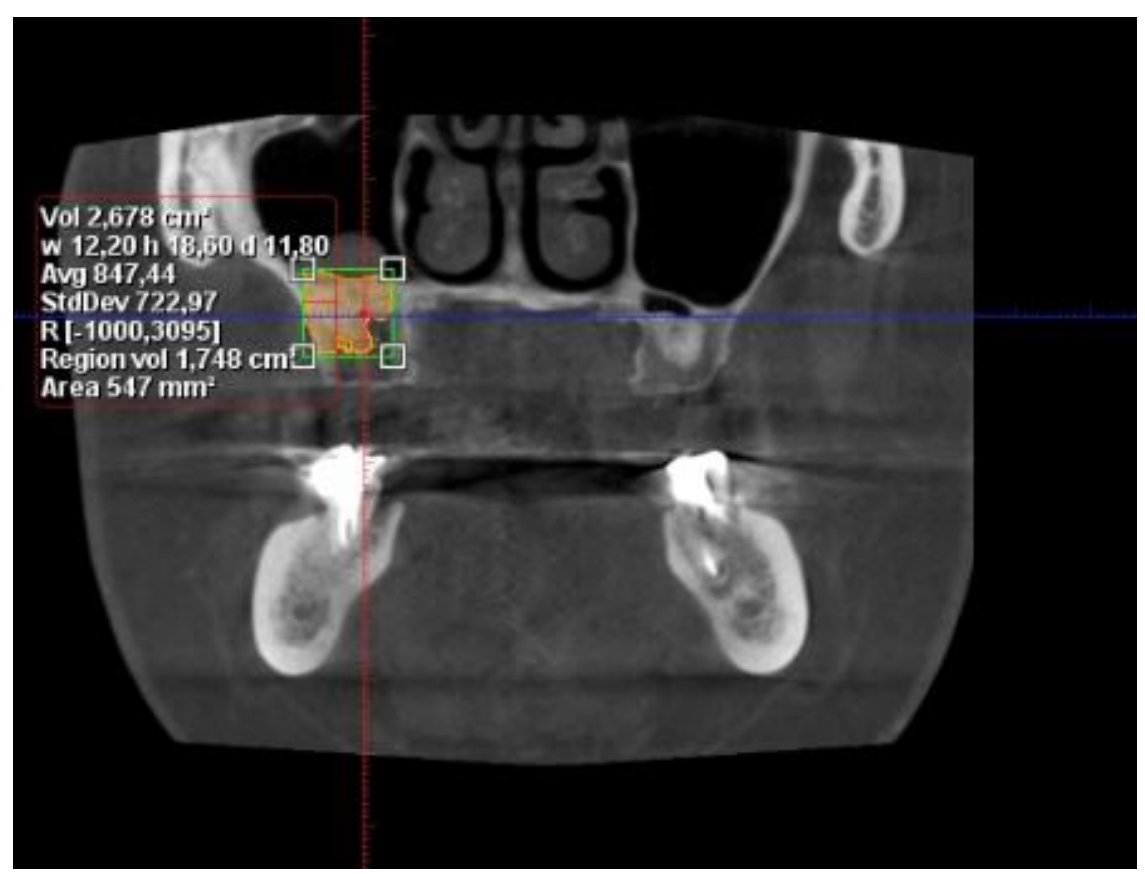

Figure 3: Measuring the bone graft volume 3 years after the maxillary sinus floor augmentation procedure

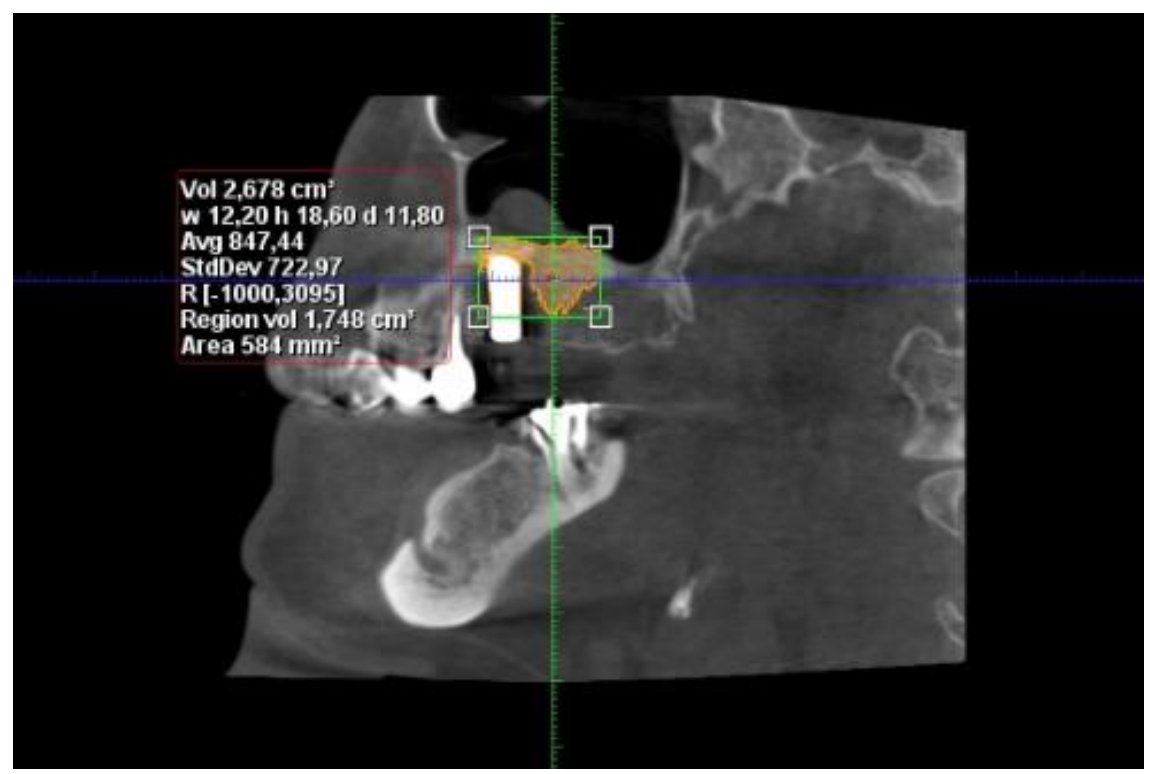

Figure 4: Measuring the bone graft volume 3 years after the maxillary sinus floor augmentation procedure

\section{Results}

The bone healingperiod following the maxillary sinus floor augmentationsurgerieswas uneventful and without complications. The patients had the usual complaints post surgery, namely swelling at the augmented site, dull pain over the first 2-3 days and occasional nosebleeds during the first 24 hours.

Haemorrhaging occurred during four of the surgical interventions due to affecting a.a.a., which was quickly managedas it had been expected. For three of the patients there was a minor sinus membrane perforation. Both types of complications did not affect the final result of the surgery and had no consequence for the study.
The bone grafting materials applied wereas follows: Xenogenic bovine hydroxyapatite material (XBHM) Cerabone of BotissDental, Berlin, Germany; synthetic biphasic calcium phosphate material (SBCPM) BoneCeramicTM Straumann, Switzerland; and biphasic calcium phosphate paste material (BCPPM) Maxresorbinject of BotissDental, Berlin.

Three years after the maxillary sinus floor augmentation procedures each patientwas referred for a follow-up CBCT scan in order to evaluate any change in the bone graft volume over time.

The results obtained by comparing the volume change of XBHMbone grafting material over time,after surgery and 3 years later, are demonstrated in Figures 5 and 6 respectively.

Volume 6 Issue 1, January 2017 www.ijsr.net 


\section{International Journal of Science and Research (IJSR) \\ ISSN (Online): 2319-7064}

Index Copernicus Value (2015): 78.96 | Impact Factor (2015): 6.391

\begin{tabular}{|c|c|c|c|c|c|c|c|c|c|c|}
\hline \multicolumn{11}{|c|}{ T-testforDependentSamples } \\
\hline \multicolumn{11}{|c|}{ Markeddifferencesaresignificantat $\mathrm{p}<, 05000$} \\
\hline & Mean & Std. Dv. & $\mathrm{N}$ & Diff. & Std.Dv. - Diff. & $\mathrm{t}$ & $\mathrm{df}$ & $\mathrm{p}$ & Confidence $-95,000 \%$ & Confidence - $+95,000 \%$ \\
\hline Cerabone after surgery & 16,566 & 0,25 & & & & & & & & \\
\hline Cerabone after 3 years & 14,228 & 0,26 & 10 & 0,233 & 0,06 & 11,50 & 9 & 0,000001 & 0,1878 & 0,2797 \\
\hline
\end{tabular}

Fig. 5The t-test for dependent samples revealeda statistically significant difference $(p=0.000001<0.05)$ for the mean values of Cerabone, showing decreasing in graft volume after 3 years of approximately 0.2338 .

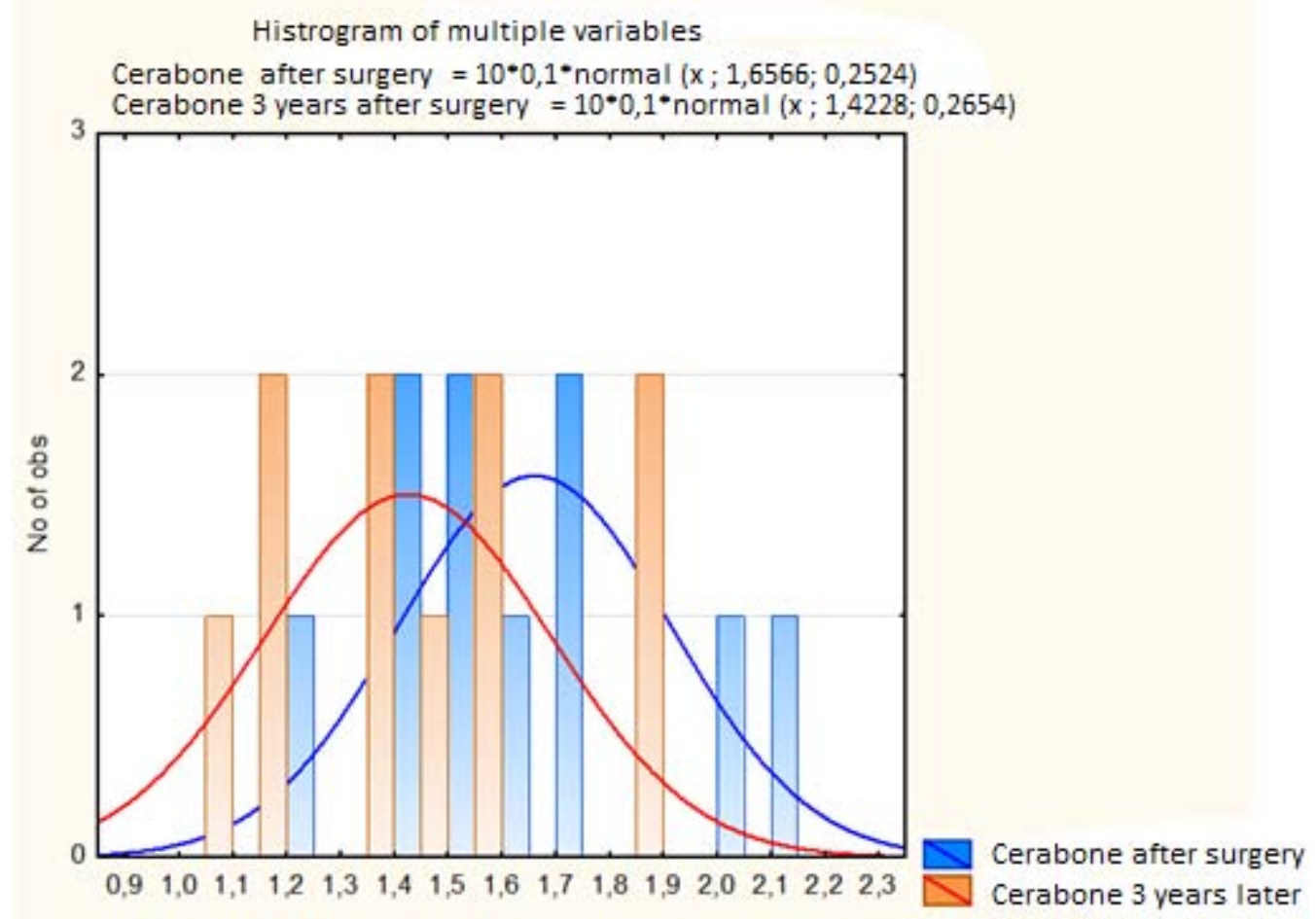

Fig. 6A histogram of the volume change of Cerabone graft material over time, 3 years after surgery
The results obtained by comparing the volume change of SBCPM bone grafting material over time,after surgery and 3 years later, are demonstrated in Figures 7 and 8 respectively.

\begin{tabular}{|c|c|c|c|c|c|c|c|c|c|c|}
\hline \multicolumn{10}{|c|}{$\begin{array}{c}\text { T-testforDependentSamples (GEORGIEV.sta) } \\
\text { Markeddifferencesaresignificantat } \mathrm{p}<, 05000\end{array}$} \\
\hline & Mean & Std.Dv. & $\mathrm{N}$ & Diff. & Std.Dv. - Diff. & $\mathrm{t}$ & $\mathrm{df}$ & $\mathrm{p}$ & Confidence - -95,000\% & Confidence - +95,000\% \\
\hline $\begin{array}{c}\text { BoneCeramic after } \\
\text { surgery }\end{array}$ & 1.6979 & 0.351627 & & & & & & & & \\
\hline $\begin{array}{c}\text { BoneCeramic after 3 } \\
\text { years }\end{array}$ & 1.3475 & 0.372375 & 10 & 0.3504 & 0.1022 & 10.8 & 9 & 0.000002 & 0.277283 & \\
\hline
\end{tabular}

Fig. 7The t-test for dependent samples revealeda statistically significant difference $(p=0.000001<0.05)$ for the mean values of BoneCeramic, showing decreasing in graft volume after 3 years of approximately0.3504. 


\section{International Journal of Science and Research (IJSR) \\ ISSN (Online): 2319-7064}

Index Copernicus Value (2015): 78.96 | Impact Factor (2015): 6.391

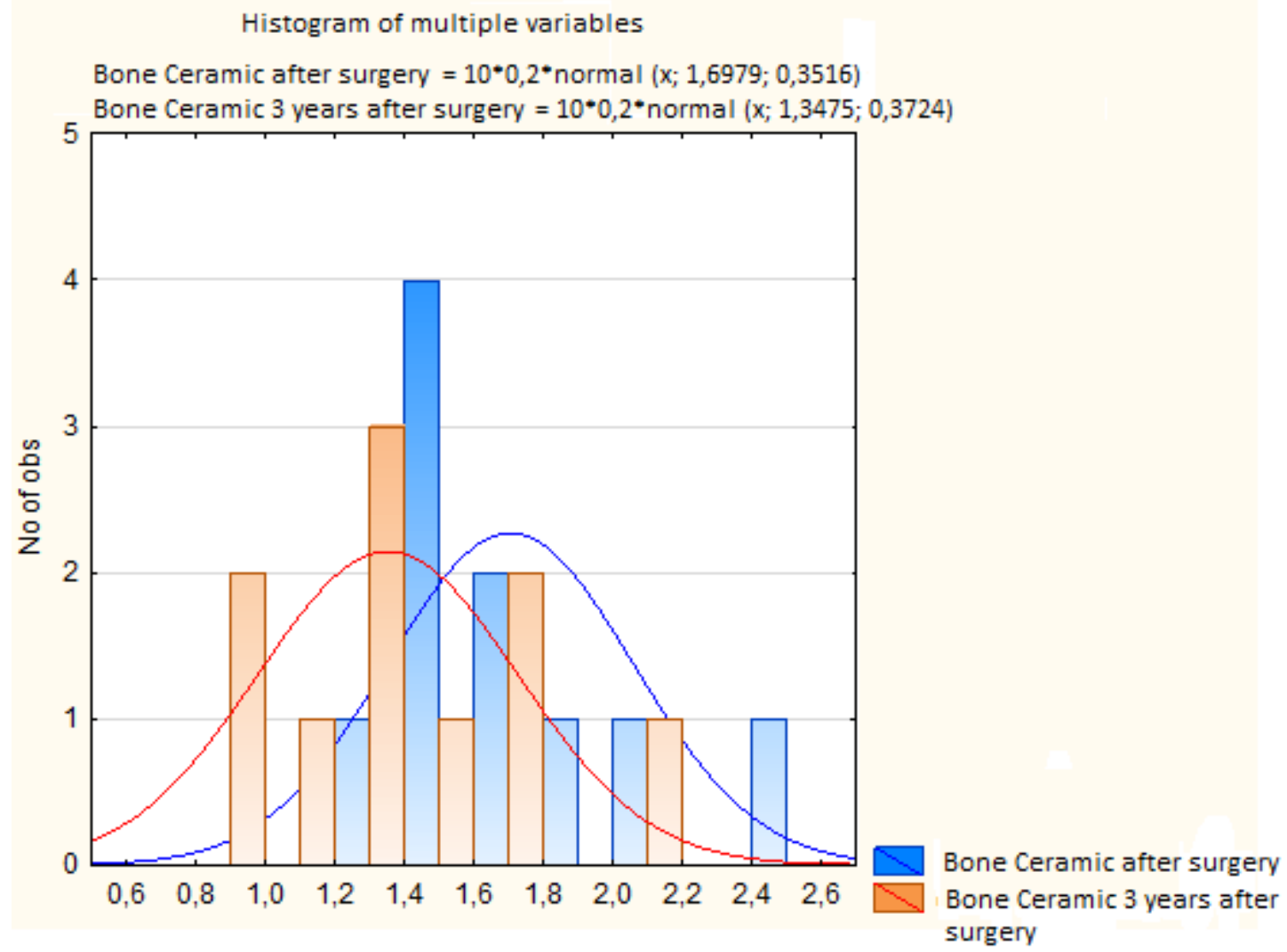

Fig. 8 A histogram of the volume change of Bone Ceramic graft material in time, 3 years after surgery.
The results obtained by comparing the volume change of BCPPM bone grafting material over time, after surgery and 3 years later, are demonstrated in Figures9 and 10 respectively.

\begin{tabular}{|c|c|c|c|c|c|c|c|c|c|c|}
\hline \multicolumn{11}{|c|}{ T-testforDependentSamples (GEORGIEV.sta) } \\
\hline \multicolumn{11}{|c|}{ Markeddifferencesaresignificantat $\mathrm{p}<, 05000$} \\
\hline & Mean & Std.Dv. & $\mathrm{N}$ & Diff. & Std.Dv. Diff. & $\mathrm{t}$ & $\mathrm{df}$ & $p$ & Confidence - $-95,000 \%$ & Confidence $-+95,000 \%$ \\
\hline Maxresorbinj after surgery & 1.3676 & 0.449091 & & & & & & & & \\
\hline Maxresorbinj after 3 years & 0.842 & 0.330356 & 10 & 0.5256 & 0.1527 & 10.884 & 9 & 0.000002 & 0.416361 & 0.634839 \\
\hline
\end{tabular}

Fig. 9The t-test for dependent samples revealeda statistically significant difference $(\mathrm{p}=0.000001<0.05)$ for the mean values of Maxresorb inject, showing decreasing in graft volume after 3 years of approximately 0.5256 . 


\section{International Journal of Science and Research (IJSR) \\ ISSN (Online): 2319-7064}

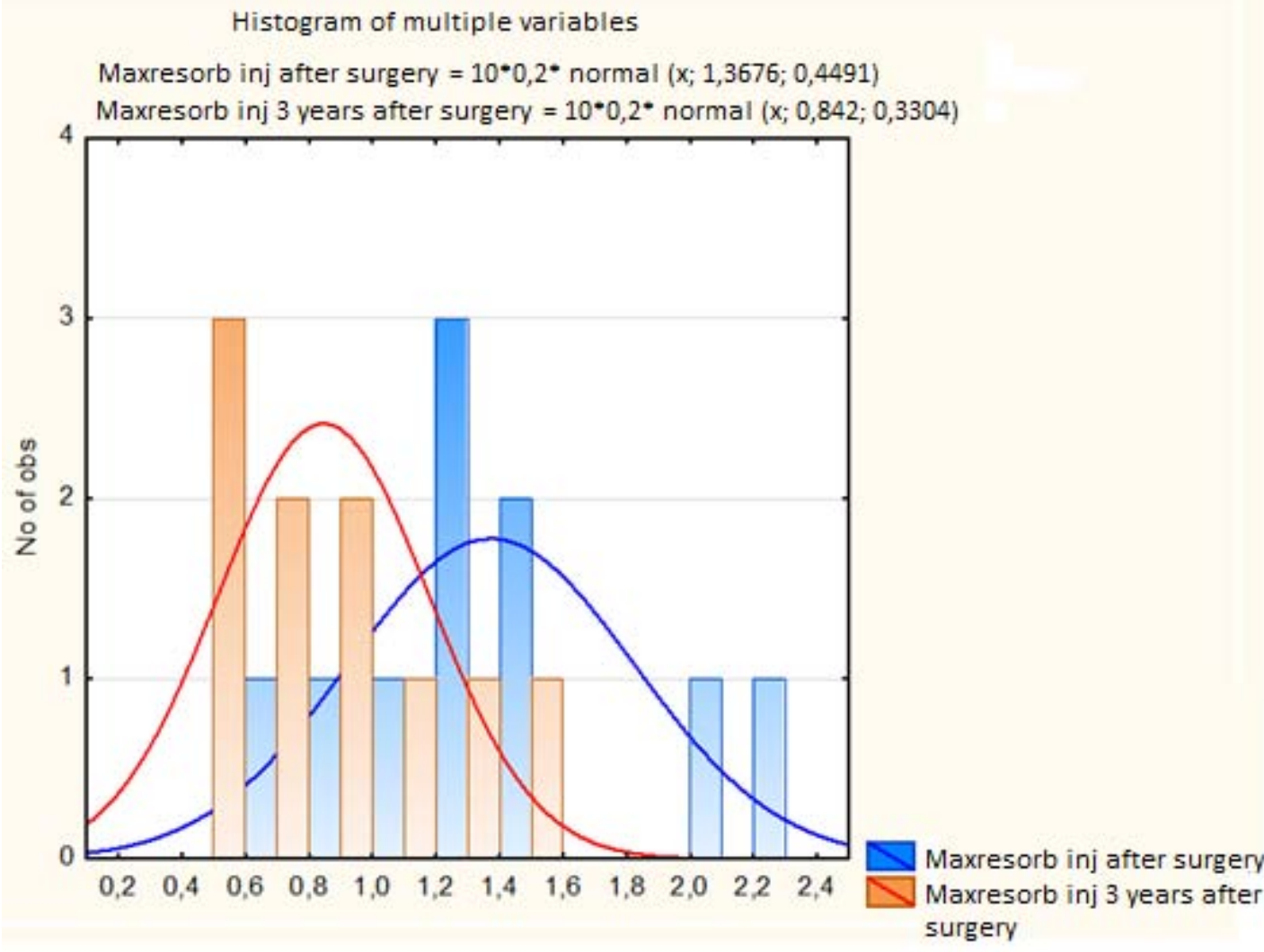

Fig. 10 A histogram of the volume change of Maxresorb inject graft material over time, 3 years after surgery. The Collagen fleece absorbedin venous blood used as bone grafting material over time,after surgery and 3 years later, are demonstrated in Figures 11 and 12 respectively. results obtained by comparing the volume change of

\begin{tabular}{|l|c|c|c|c|c|c|c|c|c|c|c|}
\hline \multicolumn{10}{|c|}{ T-testforDependentSamples (GEORGIEV.sta) } \\
\hline \multicolumn{10}{|c|}{ Markeddifferencesaresignificantat $\mathrm{p}<, 05000$} \\
\hline & Mean & Std.Dv. & $\mathrm{N}$ & Diff. & Std.Dv. - Diff. & $\mathrm{t}$ & $\mathrm{df}$ & $\mathrm{p}$ & Confidence - -95,000\% & Confidence - +95,000\% \\
\hline Collagen fleeceafter surgery & 0.5894 & 0.116944 & & & & & & & & & \\
\hline Collagen fleeceafter 3 years & 0.1794 & 0.026529 & 5 & 0.41 & 0.0951 & 9.6 & 4 & 0.000648 & 0.291901 & 0.528099 \\
\hline
\end{tabular}

Fig. 11The t-test for dependent samples revealeda statistically significant difference $(p=0.000001<0.05)$ for the mean values of Collagen fleece absorbedin venous blood, showing decreasing in graft volume after 3 years of approximately 0.410 . 
International Journal of Science and Research (IJSR)

ISSN (Online): 2319-7064

Index Copernicus Value (2015): 78.96 | Impact Factor (2015): 6.391

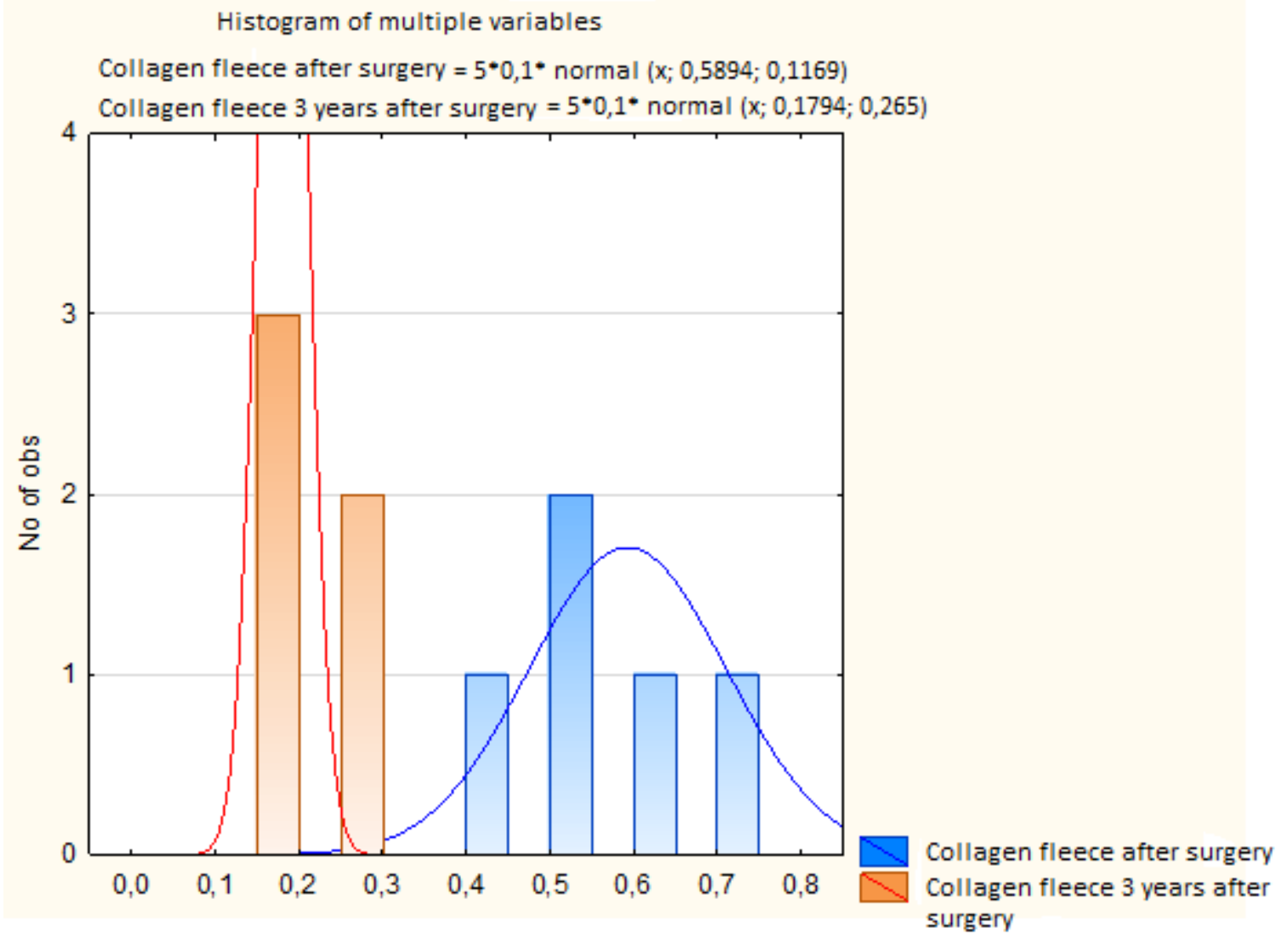

Fig. 12 A histogram of the volume change of Collagen fleece absorbedin venous bloodover time, 3 years after surgery. The various bone grafting materials applied demonstrated different volume loss over time following a maxillary sinus floor augmentation procedure. The least volume loss over time was found in the application of Xenogenic bovine hydroxyapatite material (XBHM), and most volume contraction was observed in the use of Biphasic calcium phosphate paste material (BCPPM). (Figure 13)

\begin{tabular}{|c|c|}
\hline Type of bone grafting material & $\begin{array}{c}\text { Bone graft volume } \\
\text { loss after 3 years }\end{array}$ \\
\hline Cerabone & $0.2338 \mathrm{~cm}^{3}$ \\
\hline BoneCeramic & $0.3504 \mathrm{~cm}^{3}$ \\
\hline Maxresorbinject & $0.5256 \mathrm{~cm}^{3}$ \\
\hline Collagen fleece absorbed in venous blood & $0.410 \mathrm{~cm}^{3}$ \\
\hline
\end{tabular}

Fig. 13 Comparison between bone grafting materials, applied in maxillary sinus floor augmentation procedures, and the volume loss of bone graftover a 3-year period.

\section{Discussion}

The volumetricchanges of the maxillary sinus following a maxillary sinus floor augmentation procedureare of great importance for the outcome of surgery as well as for the right stage of placing dental implants in the augmented site.A number of authors have investigated the timedependent changes in an augmented sinus.

Atef M.[16], Ohe JY.[15], Liu Y.[13], Berberi A.[10], Nishida T.[8], Dellavia [18]followed up thevolumetric changes occurring after a sinus floor augmentation procedure over a 6-month period.

Mazzocco F.[12] investigated the bone graftvolume changes following surgery over a 9-month period.

Berberi A.[10], Kim ES.[17] followed up thebone graft volume changes followinga sinus floor augmentation procedure over a 1-year period.

The time devoted by Umanjec-Korac S.[14] to explorebone graft volume changes after a sinus floor augmentation was 2 years.

Shanbhag S. et al. [7] performed a systematic literature review, observing no differences in the volume change of various bone grafting materials over time.

The present study set as an objective to follow up bone graft volume changes over a 3-year period, which had not been attempted or published yet.

The results obtained in this study displayed different values ofbone graft volumewith the application of various bone replacement materials. The best results proved to be achieved using Xenogenic bovine hydroxyapatite material (XBHM), and most resorption was observed when using Biphasic calcium phosphate paste material (BCPPM).

The data obtained from CBCT [19,20,21,22] would not be of any significance should the oral surgeon decideto perform a sinus floor lift and dental implant placement in one stage or to carry out both procedureswithin a relatively short time. It 


\section{International Journal of Science and Research (IJSR) \\ ISSN (Online): 2319-7064}

Index Copernicus Value (2015): 78.96 | Impact Factor (2015): 6.391

is not uncommon to have patients who for some reasonsafter the sinus floor augmentation procedure take a long time before the implant placement stage. In those cases it is essential to select the proper augmentation material that would maintain its volume as long as possible over time.

\section{Conclusions}

Based on a comparison of different bone replacement materials for a maxillary sinus floor augmentation procedure,the bone grafting material that maintained its volume the longest over time proved to Xenogenic bovine hydroxyapatite material.

\section{References}

[1] Stiller M, Rack A, Zabler S, Goebbels J, Dalügge O, Jonscher S, Knabe C. Quantification of bone tissue regeneration employing beta-tri calcium phosphate by three-dimensional non-invasive synchrotron microtomography--a comparative examination with his tomorphometry.Bone. 2009 Apr;44(4):619-28. doi: 10.1016/j.bone.2008.10.049. Epub 2008 Dec 3.

[2] Wanschitz F, Figl M, Wagner A, Rolf E. Measurement of volume changes after sinus floor augmentation with a phycogenic hydroxyapatite.Int $\mathrm{J}$ Oral Maxillofac Implants. 2006 May-Jun;21(3):433-8.

[3] Nyström E, Ahlqvist J, Kahnberg KE, Rosenquist JB. Autogenousonlay bone grafts fixed with screw implants for the treatment of severely resorbed maxillae. Radiographic evaluation of preoperative bone dimensions, postoperative boneloss, and changes in soft-tissue profile. Int J Oral Maxill of acSurg. 1996 Oct;25(5):351-9.

[4] Uchida Y, Goto M, Katsuki T, Soejima Y. Measurement of maxillary sinus volume using computerized to mographic images. Int $\mathrm{J}$ Oral Maxillofac Implants. 1998 Nov-Dec;13(6):811-8.

[5] Hieu PD, Chung JH, Yim SB, Hong KS. A radiographical study on the changes in height of grafting materials afters inuslift: a comparison between two types of xenogenic materials.J Periodontal ImplantSci. $2010 \quad$ Feb;40(1):25-32. doi: 10.5051/jpis.2010.40.1.25. Epub 2010 Feb 28.

[6] Baciut M, Hedesiu M, Bran S, Jacobs R, Nackaerts O, Baciut G.Pre- and post operative assessment of sinus grafting procedures using cone-beam computed to mography compared with panoramicradio graphs. Clin Oral Implants Res. 2013 May;24(5):512-6. doi: 10.1111/j.1600-0501.2011.02408.x. Epub 2012 Jan 6.

[7] Shanbhag S, Shanbhag V, Stavropoulos A.Volume changes of maxillarysinus augmentations overtime: a systematic review.Int J Oral Maxill of ac Implants. 2014 Jul-Aug;29(4):881-92. doi: 10.11607/jomi.3472.

[8] Nishida T, Takenouchi Y, Mori K, Ariji M, Nishida K, Ito $\mathrm{K}$. Remodeling of auto genous bone grafts after osteotome sinus floor elevation assessed by limited cone beam computed to mography.Int J Dent. 2013;2013:931708. doi: 10.1155/2013/931708. Epub 2013 Jul 14.

[9] Gorla LF, Spin-Neto R, Boos FB, PereiraRdos S, Garcia-Junior IR, Hochuli-Vieira E.Useofautogenousboneandbeta-tricalciumphosphate in maxillary sinus lifting: a prospective, randomized, volumetric computed to mography study.Int J Oral Maxill of ac Surg. 2015 Dec;44(12):1486-91. doi: 10.1016/j.ijom.2015.07.003. Epub 2015 Jul 29.

[10] Berberi A, Bouserhal L, Nader N, Assaf RB, Nassif NB, Bouserhal J, Salameh Z.EvaluationofThreeDimensional Volumetric Changes After Sinus Floor Augmentation with Mineralized Cortical Bone Allograft.J MaxillofacOralSurg. 2015 Sep;14(3):624-9. doi: 10.1007/s12663-014-0736-3. Epub 2014 Dec 24.

[11] Soardi CM, Zaffe D, Motroni A, Wang HL. Quantitative comparison of cone beam computed tomography and microradiography in the evaluation of bone density after maxillary sinus augmentation: a preliminary study.ClinImplantDentRelatRes. 2014 Aug;16(4):557-64. doi: 10.1111/cid.12016. Epub 2012 Nov 15.

[12] Mazzocco F, Lops D, Gobbato L, Lolato A, Romeo E, delFabbro M.Three-dimensional volume change ofgraftedboneinthemaxillarysinus.Int J Oral Maxill of ac Implants. 2014 Jan-Feb;29(1):178-84. doi: 10.11607/jomi.3236.

[13]Liu Y, Chen F, Feng Y, Xie C, Song YL, Li DH. [Maxillary sinus floor augmentation with Bio-Ossas a solegraft: a histologic, radiographic and preliminary clinical study]. [ArticleinChinese] Zhonghua Kou QiangYiXue ZaZhi. 2013 Sep;48(9):513-7.

[14] Umanjec-Korac S, Wu G, Hassan B, Liu Y, Wismeijer D. A retrospective analysis of the resorption rate of deproteinized bovineboneasm axillarysinusgraftmaterialonconebeamcomputedtomogra phy.ClinOralImplantsRes. 2014 Jul;25(7):781-5. doi: 10.1111/clr.12174. Epub 2013 Apr 17

[15] Ohe JY, Kim GT, Lee JW, AlNawas B, Jung J, Kwon YD.Volumestabilityofhydroxyapatiteand $\quad \beta$ tricalciumphosphatebiphasicbonegraftmaterialinmaxilla rysinusfloorelevation: a radiographicstudyusing $3 \mathrm{D}$ conebeamcomputedtomography.ClinOralImplantsRes. 2015 Feb 3. doi: 10.1111/clr.12551. [Epubaheadofprint]

[16] Atef M, Hakam MM, ElFaramawey MI, AbouElFetouh A, Ekram M. Non grafted sinus floor elevation with a space-maintaining titanium mesh: caseseries study on four patients.Clin Implant Dent Relat Res. 2014 Dec;16(6):893-903. doi: 10.1111/cid.12064. Epub 2013 Mar 28.

[17] Kim ES, Moon SY, Kim SG, Park HC, Oh JS.Threedimensional volumetric analysis after sinus grafts. Implant Dent. 2013 Apr;22(2):170-4 doi: 10.1097/ID.0b013e31827f3576.

[18] Dellavia C, Speroni S, Pellegrini G, Gatto A, Maiorana C. A new method to evaluate volumetric changes in sinus augmentation procedure. Clin Implant Dent Relat Res. 2014 Oct;16(5):684-90. doi: 10.1111/cid.12058. Epub 2013 Mar 19.

[19]Tihomir Georgiev ${ }^{1}$, Stefan Peev ${ }^{2}$, Hristina Arnautska ${ }^{3}$, Krasimira Prodanova ${ }^{4}$, Mariana Dimova ${ }^{5}$ Incidence and type of bony septa in the maxillary sinus in patients from Varna regionDental Review,March 2016, 62-67, ISSN: 1313-4655

[20] Tihomir Georgiev ${ }^{1}$, Stefan $\mathrm{Peev}^{2}$, Hristina Arnautska ${ }^{3}$, Krasimira Prodanova ${ }^{4}$, Mariana Dimova ${ }^{5}$ Sinus lift preoperative study of the maxillary sinus vestibular wall 


\section{International Journal of Science and Research (IJSR) \\ ISSN (Online): 2319-7064}

Index Copernicus Value (2015): 78.96 | Impact Factor (2015): 6.391

using cone beam computerized tomographyDental Review, March 2016, 97-101, ISSN: 1313-4655

[21] Tihomir Georgiev ${ }^{1}$, Stefan Peev $^{2}$, Mariana Dimova ${ }^{3}$ Radiographic assessment of the change in the maxillary sinus mucosa in proximity to endodontically treated teeth with some or no evident clinical pathological processes Dental Review, March 2016, 5-9, ISSN: $1313-4655$

[22] Tihomir Georgiev ${ }^{1}$, Stefan Peev ${ }^{2}$, Hristina Arnautska ${ }^{3}$, Elitsa Aleksieva ${ }^{4}$, Mariana Dimova ${ }^{5}$ A clinical case of intraosseous anastomosis located in the vestibular wall of the maxillary sinus between the posterior superior alveolar artery and the infraorbital artery Dental Review,March 2016, 62-67, ISSN: 1313-4655 